\title{
AVALIAÇÃO DA ESTABILIDADE DE EMULSÕES COSMÉTICAS ELABORADAS COM SAPONINAS DE JUÁ (ZIZIPHUS JOAZEIRO) E SISAL (AGAVE SISALANA)
}

\section{EVALUATION OF STABILITY COSMETIC EMULSIONS PREPARED WITH SAPONINIS OF JUA (ZIZIPHUS JOAZEIRO) AND SISAL (AGAVE SISALANA)}

\author{
Kelly Alencar SILVA ${ }^{1 *}$, Bianca Morcillo De Floriani POZZA ${ }^{1}$, Bernardo Dias RIBEIRO', \\ Maria Alice Zarur COELHO ${ }^{1}$
}

1 - Escola de Química, Centro de Tecnologia, Universidade Federal do Rio de Janeiro, Rio de Janeiro, Brasil

*Autor para correspondência: kalenkar@gmail.com

\section{Resumo:}

O estudo trata sobre o desenvolvimento de emulsão cosmética utilizando as saponinas de Juá e Sisal e a avaliação dos mecanismos de envelhecimento ao longo do tempo utilizando o processamento digital de imagem como ferramenta. Para o estudo da estabilidade física das emulsões foram mensurados o diâmetro médio das gotículas de óleo a cada 7 dias durante 90 dias de armazenamento. Além disso, testes físicos como: centrifugação, ciclo de congelamento-descongelamento, aquecimento acelerado foram conduzidos proporcionando as amostras a diferentes condições de stress. Duas emulsões permaneceram fisicamente estáveis por 90 dias eram compostas por $2,76(\mathrm{~m} / \mathrm{m})$ laureth-23, 2,51\% $(\mathrm{m} / \mathrm{m})$ álcool cetílico, $0,13 \%(\mathrm{~m} / \mathrm{m})$ de span 80 e $0,38 \%$ de saponina de $\mathrm{s}$ isal e $2,76 \%(\mathrm{~m} / \mathrm{m})$ de laureth-23, $2,51 \%(\mathrm{~m} / \mathrm{m})$ de álcool cetílico, $0,38 \%(\mathrm{~m} / \mathrm{m})$ de span 80 e $0,13 \%$ de saponina de sisal.

Palavras chaves: emulsão, cosméticos, surfactante natural, saponina, estabilidade, processamento digital de imagem

\begin{abstract}
:
This study deals about development of cosmetic emulsion using the saponins Jua and Sisal and evaluation of mechanisms of aging using digital image processing. The study of physical stability of emulsions were measured the average diameter of oil droplets every 7 days during 90 days of storage. Furthermore, physical testing as centrifugation, freeze-thaw cycle, rapid heating were conducted by providing the samples to different conditions of stress. Two emulsions remained physically stable for 90 days, it was composed of $2.76(\mathrm{w} / \mathrm{w})$ laureth-23, 2.51\% (w/w) cetyl alcohol, $0.13 \%(\mathrm{w} / \mathrm{w})$ Span 80 and $038 \%$ sisal saponin and $2.76 \%(\mathrm{~m} / \mathrm{m})$ laureth $-23,2.51 \%$ $(\mathrm{w} / \mathrm{w})$ cetyl alcohol, $0.38 \%(\mathrm{w} / \mathrm{w})$ span 80 and $013 \%$ sisal saponin.
\end{abstract}

Keywords: emulsion, cosmetics, natural surfactant, saponin, stability, digital image processing 


\section{INTRODUÇÃO}

As emulsões são consideradas sistemas termodinamicamente instáveis. Esse fato é afirmado devido à energia livre positiva necessária para aumentar a área de superfície entre as fases oleosa e aquosa e apresentarem densidades diferentes. Assim, para se produzir emulsões que sejam cineticamente estáveis cineticamente durante um período razoável de tempo é necessário a adição de emulsionantes além de uma adequada homogeneização (MCCLEMENTS E DECKER, 2000, SILVA et al., 2009).

Os principais mecanismos físico-químicos de desestabilização de emulsões descritos na literatura são: a separação gravitacional, a floculação e a coalescência. Estes processos de desestabilização são desencadeados por fatores intrínsecos e extrínsecos que incluem: a composição da emulsão, o tensoativo utilizado, o tamanho das gotículas de óleo, a viscosidade, o volume de fase dispersa, o pH, a presença de eletrólitos, as propriedades da película interfacial, o processo de fabricação e a velocidade de homogeneização (LIMA et al., 2008).

Para se elaborar emulsões que sejam cineticamente estáveis por um período razoável de tempo, é necessária a adição de surfactantes antes de homogeneização (SILVA et al., 2009). Os surfactantes utilizados neste estudo foram: Laureth-23, Span 80 e saponinas, em diferentes concentrações. As saponinas são metabólitos secundários produzidos pelas plantas e têm atividades biológicas importantes São caracterizadas por serem glicosídeos de elevado peso molecular, constituído por uma unidade de açúcar ligada a triterpeno ou aglicona.

Além destas funções, as saponinas estão sendo amplamente investigadas devido à sua propriedade hemolítica (Kaiser et al., 2010). Elas podem ser usadas para elaboração de sabões, shampoos, loções, creme de barbear e pasta de dentes (Bio-Botanica, 2004).

As propriedades físico-químicas e a estabilidade das emulsões são 
determinadas por diversos fatores, tais como a concentração do emulsionante, a fração de volume da fase oleosa para a fase aquosa, o método de mistura, o tamanho das gotas, a viscosidade, a tensão superficial e temperatura, assim como a homogeneização e outras condições de processamento empregadas (KIM et al., 2006).

A avaliação da estabilidade da emulsão pode ser estudada pela alteração no tamanho das e distribuição das gotículas de óleo. O aumento no diâmetro e volume médio das gotículas de óleo é considerado um indicativo de perda de estabilidade da emulsão e a taxa de crescimento das gotículas ao longo do tempo revela o mecanismo de ação predominante. Dois mecanismos são considerados neste estudo, a coalescência e difusão molecular (Silva et al., 2009).

Para o desenvolvimento de novas formulações emulsionadas os resultados referentes à estabilidade e vida de prateleira do produto final. Por conseguinte, o estudo das técnicas de estabilidade acelerada, como a exposição a diferentes condições de tensão e de temperatura e centrifugação nesta fase (Lima et al., 2008).

Objetivo deste estudo foi utilizar as saponinas como substituto total ou parcial dos surfactantes amplamente utilizados na indústria de cosméticos, gerando emulsões estáveis ou mais estável do que aqueles sem saponina.

\subsection{Mecanismo de envelhecimento}

A degradação física da emulsão se deve a uma tendência espontânea de redução da energia livre de Gibbs $(\Delta \mathrm{G})$, conseguida pela redução do tamanho da interface óleo/água $(\Delta \mathrm{A})$ e da tensão interfacial entre as fases contínua e dispersa $(\gamma)$ como mostrado na equação 1.

$$
\Delta \mathrm{G}=\gamma \Delta \mathrm{A}-\mathrm{T} \Delta \mathrm{S}(1)
$$

A redução da área interfacial é derivada principalmente de dois 
mecanismos: a coagulação seguida da coalescência e a difusão molecular (SILVA et al.,2010). De acordo com a teoria de Van den Tempel a degradação da emulsão por coalescência se caracteriza por uma ampliação na distribuição de tamanho das gotículas, com um aumento exponencial no tamanho médio das gotículas com o tempo como indicado na equação 2 .

$$
\overline{\mathrm{a}}^{3}=\overline{\mathrm{a}} 0^{3} \exp (\mathrm{Kt})
$$

Na qual $\bar{a} 0^{3}$ é o raio médio inicial das partículas, ā é o raio médio das partículas no tempo t e $\mathrm{K}$ é a constante de coalescência. $\mathrm{O}$ espessamento das emulsões por meio da difusão molecular se deve ao crescimento gradual das gotículas maiores de emulsão à custa das menores. Esta é uma consequência direta de efeito de Kelvin que afirma ser a solubilidade da partícula inversamente proporcional ao seu raio, significando que as moléculas individuais tendem a deixar as partículas menores e se difundir através da fase contínua para se juntar as maiores (SILVA et al., 2010).

A teoria de Lifshitz-Slyozov-Wagner afirma que o mecanismo de difusão molecular é caracterizado por um crescimento linear do tamanho das gotículas com o tempo conforme a equação 3. (FREIRE et al., 2005)

$$
d\left(a^{-3}\right) / d t=8 C D \gamma V_{m}^{2} / 9 k T
$$

Sendo C a solubilidade, D o coeficiente de difusão da fase dispersa no meio contínuo, Vm o volume molar da substância dispersa, $\mathrm{R}$ a constante normal dos gases e $\mathrm{T}$ a temperatura absoluta.

O aumento no volume das gotículas de óleo é proporcional à solubilidade, ao coeficiente de difusão e a tensão interfacial da fase dispersa (fase oleosa) na fase contínua (fase aquosa). Então, esse tipo de emulsão pode ser estabilizado pela diminuição de pelo menos um desses três fatores apresentados (TRINDADE et al., 2008). 


\section{MATERIAL E MÉTODOS}

O processamento digital de imagem foi usado para avaliar a estabilidade de emulsões pela distribuição do tamanho de gota ao longo do tempo de armazenamento à temperatura ambiente e em amostras sob condições de stress.

\subsection{Preparação das emulsões}

Para obter as emulsões cosméticas, foram preparadas duas fases (A e B). A fase A era composta de: água $(90,23 \% \mathrm{~m} / \mathrm{m})$, Carbopol $940(0,15 \% \mathrm{~m} /$ $\mathrm{m})$, Elestab HP $100(0,05 \% \mathrm{~m} / \mathrm{m})$, Elestab CPN $(0,15 \% \mathrm{~m} / \mathrm{m})$ e quantidades variáveis de span 80 e saponina. A fase A foi aquecida em banho termostatizado a $70{ }^{\circ} \mathrm{C}$ e a cada 10 minutos, foi agitada em vórtex e reaquecida em banho tesmotatizado. Este procedimento foi repetido até a solução completa de todos os componentes presentes. Enquanto a fase $A$ era aquecida em banho de água, a fase B era preparada. Assim, em um recipiente foram colocados: óleo de canola (3,65\% m / m), álcool cetílico e laureth-23 em quantidades variáveis. O recipiente foi aquecido a $60^{\circ} \mathrm{C}$, até a completa solubilização dos componentes. Quando as duas fases ( $A$ e $B$ ) estavam homogêneas, fase $B$ era vertida na fase $A$ e agitadas durante 10 minutos no vortex. Foi adicionado em primeiro lugar, a água destilada e posteriormente hidróxido de sódio $(\mathrm{NaOH})$ para neutralizar a solução e seguiu-se com agitação em vortex por 5 minutos terminando a preparação da amostra.

A tabela 1 mostra, respectivamente, as percentagens em massa dos componentes utilizados para a preparação de amostras, sem saponina e com saponinas de Juá ou sisal. 
Tabela 1: Quantidades (\%) dos componentes das amostras cosméticos sem saponina e com saponinas de Juá ou de sisal $(\mathrm{m} / \mathrm{m})$ e o valor do $\mathrm{pH}$ após elaboração.

\begin{tabular}{|c|c|c|c|c|c|c|}
\hline & Emulsão & Span 80 & Saponina & Cetyl Alcohol & Laureth-23 & $\mathrm{pH}$ \\
\hline \multirow{11}{*}{$\begin{array}{l}\text { Emulsões } \\
\text { sem } \\
\text { saponina } \\
(\mathrm{m} / \mathrm{m})\end{array}$} & 1 & 0,00 & 0,00 & 2,59 & 0,00 & 7,03 \\
\hline & 2 & 0,00 & 0,00 & 0,00 & 2,84 & 7,13 \\
\hline & 3 & 0,53 & 0,00 & 0,00 & 0,00 & 7,61 \\
\hline & 4 & 0,00 & 0,00 & 0,86 & 1,90 & 6,98 \\
\hline & 5 & 0,35 & 0,00 & 0,87 & 0,00 & 7,13 \\
\hline & 6 & 0,35 & 0,00 & 0,00 & 0,97 & 7,04 \\
\hline & 7 & 0,00 & 0,00 & 1,73 & 0,95 & 6,91 \\
\hline & 8 & 0,17 & 0,00 & 1,74 & 0,00 & 7,05 \\
\hline & 9 & 0,17 & 0,00 & 0,00 & 1,91 & 7,21 \\
\hline & 10 & 0,17 & 0,00 & 0,86 & 0,6 & 7,08 \\
\hline & 11 & 0,50 & 0,00 & 2,51 & 2,76 & 6,93 \\
\hline \multirow{24}{*}{$\begin{array}{c}\text { Emulsões } \\
\text { com } \\
\text { saponina } \\
\text { de } \\
\text { Juá }(\mathrm{m} / \mathrm{m})\end{array}$} & 12 & 0,00 & 2,08 & 0,00 & 0,00 & 6,17 \\
\hline & 13 & 0,00 & 1,38 & 0,86 & 0,00 & 6,92 \\
\hline & 14 & 0,00 & 1,38 & 0,00 & 0,96 & 6,9 \\
\hline & 15 & 0,17 & 1,39 & 0,00 & 0,00 & 7,08 \\
\hline & 16 & 0,00 & 0,70 & 1,73 & 0,00 & 6,98 \\
\hline & 17 & 0,00 & 0,69 & 0,00 & 1,90 & 6,93 \\
\hline & 18 & 0,35 & 0,71 & 0,00 & 0,00 & 6,95 \\
\hline & 19 & 0,07 & 0,26 & 1,62 & 0,35 & 6,86 \\
\hline & 20 & 0,07 & 0,26 & 0,32 & 1,79 & 7,16 \\
\hline & 21 & 0,33 & 0,26 & 0,33 & 0,36 & 7,01 \\
\hline & 22 & 0,07 & 1,30 & 0,32 & 0,35 & 7,29 \\
\hline & 23 & 0,13 & 0,52 & 0,65 & 0,72 & 7,03 \\
\hline & 24 & 0,00 & 0,06 & 0,86 & 1,90 & 7,08 \\
\hline & 25 & 0,00 & 0,13 & 0,86 & 1,89 & 7,08 \\
\hline & 26 & 0,00 & 0,26 & 0,86 & 1,89 & 7,08 \\
\hline & 27 & 0,00 & 0,52 & 0,85 & 1,89 & 7,08 \\
\hline & 28 & 0,17 & 0,07 & 0,86 & 0,96 & 7,07 \\
\hline & 29 & 0,17 & 0,13 & 0,86 & 0,96 & 7,07 \\
\hline & 30 & 0,17 & 0,26 & 0,86 & 0,96 & 7,07 \\
\hline & 31 & 0,17 & 0,52 & 0,86 & 0,95 & 7,07 \\
\hline & 32 & 0,00 & 0,50 & 2,51 & 2,76 & 7,04 \\
\hline & 33 & 0,25 & 0,25 & 2,51 & 2,76 & 7,04 \\
\hline & 34 & 0,13 & 0,38 & 2,51 & 2,76 & 7,03 \\
\hline & 35 & 0,38 & 0,13 & 2,51 & 2,76 & 7,04 \\
\hline \multirow{8}{*}{$\begin{array}{c}\text { Emulsões } \\
\text { com } \\
\text { saponina } \\
\text { de } \\
\text { Sisal } \\
(\mathrm{m} / \mathrm{m})\end{array}$} & 36 & 0,00 & 0,69 & 0,86 & 0,95 & 6,92 \\
\hline & 37 & 0,17 & 0,70 & 0,87 & 0,00 & 7,13 \\
\hline & 38 & 0,17 & 0,70 & 0,00 & 0,96 & 7,04 \\
\hline & 39 & 0,13 & 0,52 & 0,65 & 0,72 & 7,10 \\
\hline & 40 & 0,06 & 0,26 & 0,35 & 1,62 & 6,92 \\
\hline & 41 & 0,17 & 0,26 & 0,86 & 0,96 & 7,01 \\
\hline & 42 & 0,13 & 0,38 & 2,51 & 2,76 & 6,90 \\
\hline & 43 & 0,38 & 0,13 & 2,51 & 2,76 & 7,08 \\
\hline
\end{tabular}




\subsection{Análise de imagem}

A determinação do tamanho de gotículas da emulsão foi realizada utilizando $10 \mu \mathrm{L}$ das amostras em lâmina após diluição de $40 \mu \mathrm{L}$ da amostra em $400 \mu \mathrm{L}$ de água destilada. Esse estudo foi realizado ao longo de 90 dias para as amostras que permaneceram estáveis durante esse período. Assim, as amostras foram analisadas a cada 7 dias durante 90 dias subsequentes utilizando um microscópio óptico (Eclipse E200, Nikon®) com ampliação de 100X juntamente com câmera digital (Media Cybernetics®) ligado a um computador pessoal.

A análise de imagem consistiu em três etapas. O primeiro passo foi a binarização da imagem, que é a conversão da imagem capturada a preto e branco e a remoção de ruído. Neste passo, uma imagem binária, foi criada a partir de uma imagem intensa com base num limiar de luminância, um filtro é usado para remover o ruído, as estruturas ligadas a borda da imagem são suprimidas e uma máscara criada anteriormente foi usada para a erosão da imagem binária e reconstrução morfológica.

O segundo passo foi a quantificação das gotículas através da medida do diâmetro de gotícula, do volume das gotas, da área da gotícula, e nitidez. O terceiro passo foi a avaliação de parâmetros estatísticos. A análise estatística dos dados obtidos a partir de várias imagens foi realizada para avaliar o número total de objetos analisados, o diâmetro médio das gotas de óleo e o seu desvio padrão. Além disso, foi obtido o valor quanto ao arredondamento das gotas de óleo, útil para a confirmação de que outro tipo de partícula não estaria sendo contabilizada durante o processamento.

A utilização deste procedimento automatizado descrito acima permitiu a análise de um grande número de objetos com maior precisão e rigor, em comparação com quantificação manual. Este procedimento automatizado de processamento de imagem foi desenvolvido utilizando um programa desenvolvido em Matlab® v.7.0.4 (The Mathworks, Natick, Mass). Um micrômetro e o software Imagem-Pro®, foram utilizadas para a calibração do tamanho das gotículas de óleo (SILVA et al., 2010).

Para cada amostra, foi analisada uma média de 50 imagens diferentes contendo diversas gotículas de óleo da emulsão. As emulsões em condições de stress também foram submetidas a este tratamento, entretanto, neste caso, apenas 40 imagens diferentes foram analisadas. O grau de arredondamento dos objetos foi definido como a razão entre o valor do eixo máximo (Fmax) e doo eixo mínimo (Fmin) medido para cada objeto. O círculo apresenta esta razão (Fmax / Fmin) igual à unidade $(1,0)$ (SILVA et al., 2008). 
Uma análise estatística dos dados experimentais foi efetuada para todas as amostras, devido a importância de assegurar que o processo de análise de imagem digital detectava gotas minúsculas e confirmar que as emulsões foram analisadas de forma aleatória, sem detecção de tamanho de gota preferencial. Pode afirmar-se que quando os erros sistemáticos não estão presentes, o tamanho das gotículas da população segue uma distribuição Gaussiana

\subsection{Teste de centrifugação}

As amostras que permaneceram estáveis na primeira semana de preparo (7 dias) seguiram para a etapa de centrifugação. Etapa inicial do estudo de estabilidade, qualquer sinal de instabilidade indica necessidade de reformulação. Se aprovado o produto deve seguir para os testes de estabilidade (ANVISA, 2004).

Em um eppendorf foi adicionado $1 \mathrm{~mL}$ de cada emulsão e submetido a ciclos de 1000, 2000, 3500 rpm durante 15 minutos à temperatura ambiente ( $\left.25^{\circ} \mathrm{C}\right)$ (LIMA et al., 2008).

\subsection{Estresse térmico}

As amostras estáveis após o procedimento de centrifugação seguiram para essa etapa na qual foi realizado um estudo de estabilidade preliminar. As emulsões cosméticas $(3 \mathrm{ml})$ foram acondicionadas em tubos Falcon e submetidas a aquecimento em banho termostatizado a temperatura de $40^{\circ} \mathrm{C}$. Essa temperatura foi gradativamente aumentada a cada $5^{\circ} \mathrm{C} \pm 1^{\circ} \mathrm{C}$ até $80^{\circ} \mathrm{C}$, mantendo o aquecimento por 30 minutos. A leitura foi realizada no término do aquecimento $\left(80^{\circ} \mathrm{C}\right)$, após arrefecimento natural da amostra (LIMA, 2008). As amostras que permaneceram macroscopicamente estáveis cotinuaram a serem avaliadas.

\subsection{Ciclo de congelamento-descongelamento}

Para essa etapa, as amostras foram submetidas a $4{ }^{\circ} \mathrm{C} \pm 2^{\circ} \mathrm{C} / 24$ horas (geladeira Consul( $)$ ), e a $45^{\circ} \mathrm{C} \pm 2^{\circ} \mathrm{C} / 24$ horas (estufa de secagem), completando assim o 1 ciclo. As leituras foram realizadas antes do início do ensaio e no fim do sexto ciclo (12 dias). Foram utilizados os mesmos parâmetros para avaliar do teste de estresse térmico (LIMA et al., 
2008). As amostras que permaneceram macroscopicamente estáveis continuaram a serem avaliadas.

\subsection{Teste de estabilidade acelerada}

As emulsões foram colocadas em tubos falcon e seladas, $3 \mathrm{~mL}$ das emulsões consideradas estáveis por meio de ensaios preliminares foram submetidas a condições de temperatura variável: uma foi armazenada a $4{ }^{\circ} \mathrm{C} \pm 2^{\circ} \mathrm{C}$, outra à temperatura ambiente sem sol $\left(25^{\circ} \mathrm{C} \pm 2^{\circ} \mathrm{C}\right)$, outra foi armazenada ao sol, e outra foi exposta a $45^{\circ} \mathrm{C} \pm 2^{\circ} \mathrm{C}$ (LIMA et al., 2008). As leituras foram realizadas no início do teste (imediatamente após a preparação) e a cada 7 dias até o dia 91 . Os parâmetros avaliados foram: diâmetro de gotas, o volume de gota, a área da gota e nitidez de partículas. As amostras que permaneceram macroscopicamente estáveis cotinuaram a serem avaliadas.

\section{RESULTADOS E DISCUSSÃO}

Atendendo a expectativa de diversos consumidores de produtos cosméticos a partir de produtos naturais foi escolhida para o desenvolvimento desta pesquisa, a saponina de Juá e de Sisal. Ambas possuem propriedades tensoativas em sistemas emulsionados.

A presença de substâncias tensoativas torna possível a formação de uma estrutura de creme e são os principais responsáveis para a estabilidade das emulsões durante o período de armazenamento (KORHONEN, 2001). As propriedades físico-químicas e a estabilidade das emulsões formadas são determinadas por diversos fatores, tais como a concentração do emulsionante, a fração de volume da fase oleosa para a fase aquosa, o método de mistura, o tamanho das gotas, a viscosidade, a tensão superficial e temperatura, assim como a homogeneização e outras condições de processamento empregadas (KIM et al., 2006).

A Tabela 2 mostra as equações ajustadas que podem descrever o provável mecanismo de envelhecimento responsável pela perda de estabilidade de emulsões cosméticas neste estudo, bem como os coeficientes de correlação. As emulsões apresentaram aproximadamente $90 \%$ de objetos circulares, indicando que não houve grande interferência de outros objetos. 
Tabela 2: Mecanismos Coeficiente de correlação de perda das emulsões estabilidade que se manteve estável pelo menos 42 dias ( $\bar{a} 3=$ gotículas de diâmetro $(\mu \mathrm{m} 3)$ e $\mathrm{t}=$ tempo (dias)).

\begin{tabular}{ccc}
\hline $\begin{array}{c}\text { Emulsões } \\
\text { estáveis }\end{array}$ & Equação ajustada & $\mathbf{R}^{2}$ \\
\hline 11 & $\overline{\mathrm{a}}^{3}=23,254 \mathrm{e}^{0,026 \mathrm{t}}$ & 0,85 \\
42 & $\overline{\mathrm{a}}^{3}=0,4052 \mathrm{x}+20,364$ & 0,89 \\
43 & $\overline{\mathrm{a}}^{3}=0,2981 \mathrm{x}+16,832$ or $\overline{\mathrm{a}}^{3}=18,288 \mathrm{e}^{0,0101 \mathrm{x}}$ & 0,98 \\
\hline
\end{tabular}

Entre as 43 emulsões preparadas, apenas 3 emulsões permaneceram visualmente estáveis e homogêneas, sem separação de fases durante mais de 30 dias de armazenamento (as emulsões 11, 42 e 43). Posteriormente, somente a emulsão 11 sofreu separação visual de fases. O resultado obtido através da análise de processamento de imagem revelou que as emulsões já tinham iniciado o processo de perda de estabilidade no dia 42.

Apesar da emulsão 11 se manter estável por causa da proporção de Span 80, álcool cetílico e laureth - 23 esta emulsão apresentou tendência de perda de estabilidade ao longo do tempo por coalescência, como mostrado pela equação exponencial na tabela 2. Mas a proporção da largura entre os picos da gaussiana da emulsão 11, revelou que esta apresentou caráter homogêneo e estável, já que não houve variação da média do volume das emulsões.

Por outro lado, as emulsões de 42 e 43 contendo saponina de sisal, mostrou que, dependendo da quantidade de Span 80 e saponina a estabilidade pode mudar. Uma vez que a emulsão $42(0,13 \mathrm{~m} / \mathrm{m}$ de Span 80 e 0,38 m / m Saponina de sisal) apresentou tendência de perda de estabilidade por mecanismo de difusão molecular que mostrou uma emulsão homogénea, mas com aumento linear do diâmetro médio ao longo do tempo (Tabela 2).

Já a emulsão 43 (0,38 m / m de Span 80 e 0,13 m / m Saponina de sisal) não foi possível observar o tipo de mecanismo de envelhecimento predominante (coalescência ou difusão molecular), mas esta emulsão mostrou-se heterogênea 
(Tabela 2 e Figura 1).

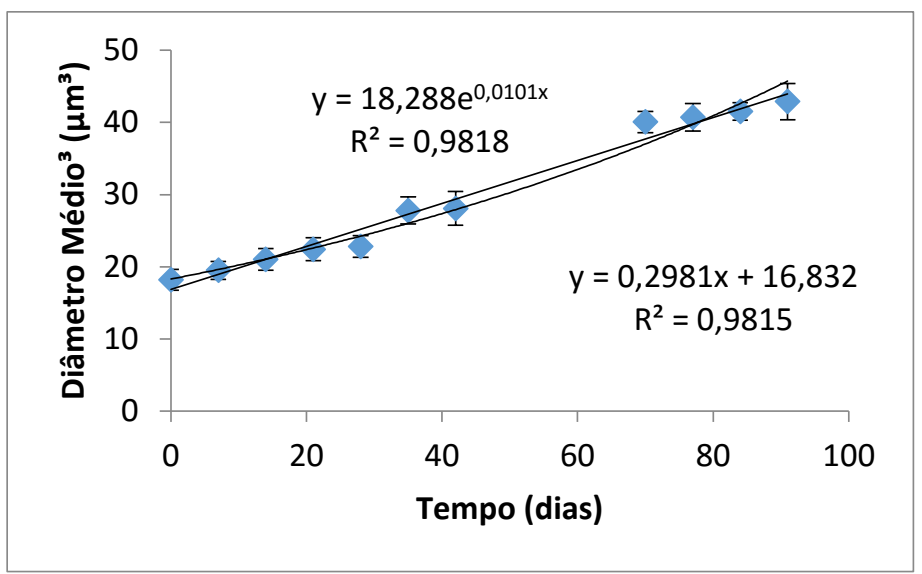

Figura 1: Evolução da dimensão das gotículas, em função do tempo para a amostra 43.

De acordo Mitra e Dunga (1997), entre as propriedades das saponinas, a concentração micelar crítica (CMC), a densidade máxima de superfície e o número de agregação (número de monómeros em uma micela) são de grande importância para a aplicação como agentes tensoativos e agentes de formação de espuma. Estes são influenciados por variáveis tais como a temperatura, a concentração de sal, o pH de fase aquosa, a concentração de solvente e do tipo (etanol, metanol). Além disso, as micelas formadas em soluções aquosas podem variar em tamanho e forma, dependendo do tipo de saponina.

Nesse estudo, foi possível concluir que não é possível substituir totalmente qualquer um dos agentes tensoativos neste tipo de emulsão cosmética, entretanto alguns componentes podem ser parcialmente substituídos pela saponina. Além disso, é necessária uma combinação de agentes tensoativos de modo a que uma possa complementar as propriedades de outro (KORHONEN, 2001).

O ensaio de centrifugação foi usado para eliminação algumas emulsões. Neste teste, foi utilizada a força centrífuga para acelerar a sedimentação, coalescência ou cremeação do sistema, mostrando rapidamente, possíveis processos de instabilidade. As emulsões 42 e 43 (figura 2) foram as únicas aprovadas pelo teste de centrifugação e, em seguida, submetidas a outras condições de estresse, como o estresse térmico, o ciclo de congelamento / descongelamento. 

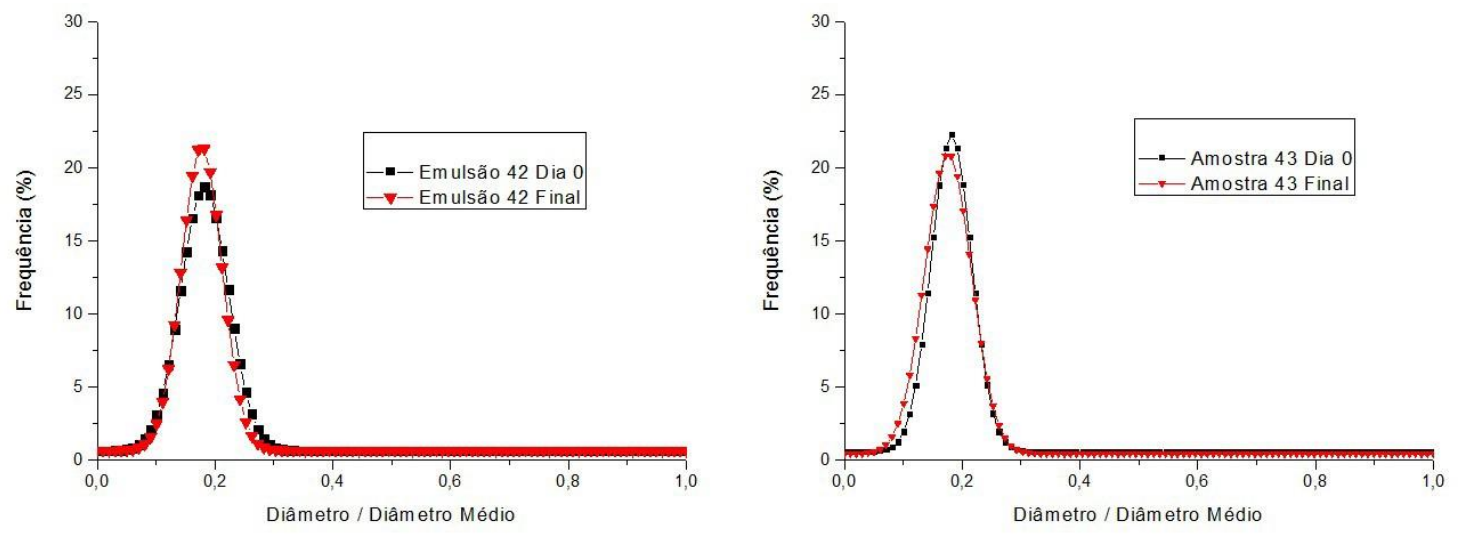

Figura 2. Distribuição de tamanho das gotículas para a amostra 42 e 43 no dia 0 e após a centrifugação.

As emulsões 42 e 43 foram as únicas que permaneceram visualmente estáveis, pois não apresentaram separação de fases. No entanto, de acordo com os resultados do processamento de análise de imagem ao longo dos dias de armazenamento, somente a emulsão 42 pode ser caracterizado como homogéneo, já que a média do volume das gotas de óleo não apresentou alteração significativa. Entretanto, após o procedimento de estresse térmico e o ciclo de congelamento / descongelamento a emulsão 42 mostrou um deslocamento da média do volume das gotas de óleo para valores mais elevados (Tabela 3). E a amostra 43 após estresse térmico apesar de ter se tornado heterogênea não apresentou aumento do volume médio para valores maiores, pois a razão entre os picos do dia 0 e após estresse térmico ficou abaixo de 1,0.

Tabela 3: Parâmetros da distribuição Gaussiana do tamanho das micelas por emulsão no início (Dia 0) e após stress térmico.

\begin{tabular}{ccccccc}
\hline & \multicolumn{3}{c}{ Largura } & \multicolumn{3}{c}{ Pico } \\
\hline Amostra & Dia 0 & Após stress & Razão & Dia 0 & Após stress & Razão \\
\hline 42 & 0,0813 & 0,0930 & 1,1439 & 0,1820 & 0,1995 & 1,0964 \\
43 & 0,0686 & 0,0873 & 1,2734 & 0,1819 & 0,1706 & 0,9379 \\
\hline
\end{tabular}


Ambas as emulsões foram submetidas a teste de centrifugação, estresse térmico, ciclos de congelamento / descongelamento e teste de estabilidade acelerada por 90 dias. As emulsões desestabilizaram em 21 dias, quando submetidos a estresse térmico.

\section{CONCLUSÕES}

Este trabalho mostrou que a análise da imagem digital é indicada para a estabilidade estudo de emulsões cosméticas e foi possível observar à influência de algumas variáveis adicionadas a composição. Observou-se que são necessários mais pontos de avaliação durante cada semana de análise para que o processamento digital de imagem possa determinar com maior precisão o mecanismo de envelhecimento. No entanto, os resultados apresentados mostraram que o uso de saponina de sisal (Agave sisalana) em tais formulações provaram ser mais apropriada do que saponina de Juá (Ziziphus joazeiro). Embora não tenha sido possível substituir completamente os tensoativos por saponinas, foi possível reduzir a quantidade de alguns ingredientes utilizados. E assim, foi possível obter um aumento de mais de $50 \%$ do tempo de estabilidade física das emulsões cosméticas avaliadas.

\section{AGRADECIMENTOS}

Este trabalho foi parcialmente financiado pela Coordenação para a Fundação de Pesquisa do Estado do Rio de Janeiro - FAPERJ e pelo Conselho Nacional de Desenvolvimento Científico e Tecnológico - CNPq.

\section{REFERENCIAS}

Bio-Botanica. (2004). Bio-Saponins. Hauppauge, New York, United States.

FREIRE, M., DIAS, A., COELHO, M., COUTINHO, J., I.M., M. ( 2005). Aging mechanism of perfluorocarbon emulsions using image analysis. Journal of Colloid and Interface Science, págs. 224-232.

KAISER, S., PAVEI, C., ORTEGA, G. (2009). Estudo da relação estrutura-atividade de saponinas hemolíticas e/ou imunoadjuvantes mediante uso de análise multivariada. Revista 
Brasileira de Farmacognosia, 300-309.

KIM, E.A. DECKER, D. JULIAN MCCLEMENTS. (2006). Preparation of multiple emulsions based on thermodynamic incompatibility of heat- denatured whey protein and pectin solutions. Food Hydrocolloids, 20 (5), pp. 586-595.

LIMA, C., VILELA, A., SILVA, A., PIANNOVVSKI, A., SILVA, K., CARVALHO, V., y otros. (2008). Desenvolvimento e avaliação da estabilidade física de emulsões O/A contendo óleo de babaçu (Orbignya oleifera). Revista Brasileira Farmaceutica, pp. 239-245.

McCLEMENTES, D. J. (1999). Food emulsions - Principle, Practice and Thechniques. London: LLC

MITRA, S., DUNGAN, S.R. (1997) Micellar properties of quillaja saponin. 1. Effects of temperature, salt and pH on solution properties. Journal of Agriculture Food Chemicak, 45, pp. 1587-1595. SILVA, K. A. (2008). Dissertação de mestrado desenvolvida no Programa de PósGraduação em Ciências de Alimentos pelo Instituto de Química da Universidade Federal do Rio de Janeiro como parte dos requisitos necessários à obtenção de grau de mestre em ciências.

SILVA, K. A., ROCHA-LEAO, M. H., COELHO, M. A. (2009). Journal of Food Engeneering. Evaluation of aging mechanisms of olive oil-lemon juice emulsion through digital image analysis, pp. 335-340.

Trindade, J., Freire, M., Amaral, P., Coelho, M., Coutinho, J., Marrucho, I. (2008). Aging mechanism of oil-in-water emulsions based on a bioemulsifier produced by Yarrowia lipolytica. Colloids and Surfaces A: Physicochemical and Engineering Aspects. 